\title{
MENGUAK RAHASIA PRIBADI ABRAHAM ATAS KUALITAS KEIMANANNYA PADA ALLAH BAPA \\ (Fredy Simanjuntak, M.Th)
}

\begin{abstract}
Abstraksi: Abraham adalah salah satu tokoh terpenting dalam Perjanjian Lama. Melalui Abraham, Tuhan menegakkan sebuah perjanjian dengan seluruh umat manusia. Abraham menunjukkan tekad yang besar untuk mematuhi perjanjian Allah yang didirikan melalui dia. Dia menerima apa yang penting untuk menjadi orang benar di mata Tuhan. Abraham menjadi tokoh yang sangat populer dan diklaim sebagai Bapa orang Yahudi, Muslim dan Kristen. Tidaklah berlebihan jika disebut sebagai Bapa segala bangsa karena memang dari keturunnyalah lahir bangsa-bangsa di dunia. Dalam Kejadian 11:27-32 dijelaskan bahwa Abraham merupakan anak dari Terah dan menetap di tanah Ur-Kasdim (bagian timur Irak), mereka adalah keluarga penyembah allah lain atau berhala sama seperti yang dilakukan oleh orangorang lain yang ada di Ur-Kasdim (Yosua 24:2). David F. Hison menjelaskan, bahwa penduduk Ur dan Haran ternyata menyembah dewa yang sama, yaitu dewa bulan, yang mereka sebut Sin. ${ }^{1}$ Dari seluruh kisah kehidupan Abraham dalam Alkitab dan bagaimana Abraham di kenal sebagai tokoh yang bepegaruh dan menginspirasikan iman banyak orang percaya.

Kata Kunci: Pribadi, Abraham, Kualitas iman, Allah Bapa
\end{abstract}

\section{Pendahuluan}

Abraham adalah generasi ke sepuluh dari Nuh melalui Sem dan dilahirkan 352 tahun setelah Air Bah, pada tahun 2018 SM. ${ }^{2}$ Meskipun Abraham yang pertama disebutkan di antara ketiga putra Terah, di Kejadian 11:26, ia bukan putra sulung. Alkitab memperlihatkan bahwa Terah berusia 70 tahun ketika putra pertamanya dilahirkan, dan bahwa Abraham lahir 60 tahun kemudian ketika ayahnya, Terah, berusia 130 tahun. (Kej 11:32; 12:4) Abraham disebutkan pada urutan pertama di antara putra-putra ayahnya

\footnotetext{
${ }^{1}$ Hinson, David F, "Sejarah Israel pada zaman Alkitab", BPK Gunung Mulia, Jakarta 2004, hal 49

${ }_{2}^{2}$ Diakses dari, https://wol.jw.org/id/wol/d/r25/lp-in/1200000060, 21 Mei 2018.
} 
karena kesetiaannya yang luar biasa dan karena ia adalah orang yang terkemuka dalam Alkitab. Ini adalah kebiasaan yang diikuti sehubungan dengan beberapa pria beriman yang menonjol lainnya, seperti Sem dan Ishak.-Kej 5:32; 11:10; 1Taw 1:28.

Selanjutanya sebagaimana yang dikatakan alkitab bahwa kehidupan Abraham selalu berpindah-pindah dan menetap di dalam kemah. Miller dan Hays mencatat dalam bukunya,

This peaceful family migration is further explained in the book, The Hisrory of Israel and Judah: "Abraham's father had left Ur of the Chaldees to migrate to the land of Canaan but had settled in the vicinity of Haran in upper Mesopotamia. After his father's death, Abraham himself migrated from Haran to Canaan. There he lived as a "sojourner" in the land; that is, he maintained his life-style as a tent dweller and resisted integration into the indigenous village-agricultural society of the land. God promised Abraham that someday the whole land would belong to his descendants and that his descendants would be great in number. Eventually Abraham made permanent camp near Hebron and became the father of two sons. ${ }^{3}$

Migrasi keluarga yang damai ini dijelaskan lebih lanjut dalam buku, The Hisrory of Israel dan Yehuda: "Ayah Abraham telah meninggalkan Ur dari Kasdim untuk bermigrasi ke tanah Kanaan tetapi telah menetap di sekitar Haran di Mesopotamia bagian atas. Setelah ayahnya kematian, Abraham sendiri bermigrasi dari Haran ke Kanaan. Di sana ia hidup sebagai "pendatang" di tanah itu; Artinya, ia mempertahankan gaya hidupnya sebagai penghuni tenda dan menolak berintegrasi ke dalam masyarakat desapertanian pribumi. Tuhan berjanji kepada Abraham itu suatu hari nanti seluruh tanah akan menjadi milik keturunannya dan keturunannya akan menjadi besar jumlahnya. Akhirnya Abraham membuat kemah permanen dekat Hebron dan menjadi ayah dari dua putra. ${ }^{4}$

Kejadian 12:1 Berfirmanlah TUHAN kepada Abraham: "Pergilah dari negerimu dan dari sanak saudaramu dan dari rumah bapamu ini ke negeri yang akan Kutunjukkan kepadamu.

\footnotetext{
3 J.Maxwell Miller \& John H. Hays, A History of ancient Israel and Judah,(London, Westminster Press :1986), hal 55
} 
Abraham was a citizen of Ur of the Chaldees, possibly in the area of where the Garden of Eden once stood. Abraham's people built the city of Babylon and Babel, the great tower. Despite their culture, the people and his family were idol worshipers. ${ }^{5}$

Abraham adalah seorang warga Ur dari Kasdim, mungkin di daerah di mana Taman Eden pernah berdiri. Orang-orang Abraham membangun kota Babel dan Babel, menara besar. Meskipun budaya mereka, orang-orang dan keluarganya adalah penyembah berhala.

Yosua 24:2 Berkatalah Yosua kepada seluruh bangsa itu: "Beginilah firman TUHAN, Allah Israel: Dahulu kala di seberang sungai Efrat, di situlah diam nenek moyangmu, yakni Terah, ayah Abraham dan ayah Nahor, dan mereka beribadah kepada allah lain.

Dengan iman Abraham, ketika dia dipanggil, taat dengan pergi ke suatu tempat yang akan dia terima untuk sebagai sebuah warisan; dan dia keluar, tidak tahu ke mana dia pergi. Dengan iman ia hidup sebagai orang asing di tanah perjanjian tersebut, seperti di negeri asing, berdiam di tendatenda.

Leon Morris mencatat, "Untuk pria berbudaya di abad pertama, kota adalah bentuk tertinggi dari keberadaan beradab". ${ }^{6}$ Kota ini menunjukkan tempat tinggal permanen. Tidak ada yang lebih tidak aman daripada tinggal di tenda. Kota ini melambangkan keabadian karena memiliki fondasi. Tapi sebagai seorang pribadi yang sanggup mempertaruhkan seluruh kenyamanan dan keamanan tersebut Abraham memilih untuk mengikuti apa yang Tuhan katakana kepadanya untuk pergi dari tempat tinggalnya.

Kehidupan Abraham sangat menarik bagi signifikansi ke arah mana sesungguhnya iman kekristenan menemukan tolok ukur dewasa ini. Mengapa? Karena kepadanyalah Allah berfirman, "Semua keluarga di bumi pasti akan memperoleh berkat melalui engkau." Akan tetapi, agar Abraham dapat memenuhi peranan tersebut dalam maksud-tujuan Allah, ia harus

\footnotetext{
${ }^{5}$ Lester Sumrall, Abraham Faith Under Siege, (United States of America, LeSEA Publishing Company: 1985), hal

${ }^{6}$ Tremper Longman III , David E. Garland, Hebrews-Revelation, Expository Bible Commentary, vol. 12, (1981), hal 118
} 
membuktikan bahwa dirinya adalah orang yang beriman dan taat kepada Allah

Dari seluruh cerita yang dikisahkan tentang Abraham dapat diajukan pertanyaan, Bagaimana kualitas iman Abraham? Apakah kualitas iman Abraham mempengaruhi kepribadian Abraham? Seandainya jika diteliti kehidupan Abraham tentang seluruh rekam jejaknya dalam Alkitab bagaimana mungkin ia layak disebut sebagai bapak orang beriman? Ruang lingkup dari penelitian ini terbatas pada kisah kehidupan pribadi dan iman Abraham yang mengindikasikan seolah adanya inkoherensi antara Perjanjian Lama dengan Perjanjian Baru. Penelitian ini juga dibatasi pada evaluasi kritis terhadap pribadi dan iman Abraham tersebut dengan didasarkan pada pemahaman teologis alkitabiah dan historis. Selanjutnya, penelitian diarahkan kepada benarkah keimanan Abraham di hadapan Allah, serta implikasi bagi gereja dalam menyikapi bagaimana sebenarnya iman yang berkualitas itu, baik yang terkait langsung maupun tidak langsung dengan Abraham.

Penulis mengamati adanya indikasi bahwa Abraham seolah-olah pernah meragukan janji Tuhan kepadanya. Dalam pandangan yang lebih jauh nampaknya Abraham belum mampu mengimani janji Allah secara progressif. Dari pemaparan di atas perlu dipahami makna yang terbungkus dalam dua hal yang terlihat seolah berseberangan, dalam hal ini berbicara tentang kualitas kepribadian dan iman Abraham.

Pertama, penulis mendapati adanya inkoherensi yang signifikan antara pribadi Abraham atas kualitas keimanannya kepada Allah Bapa menurut Perjanjian Lama ataupun perjanjian Baru?

Kedua, salah satu implikasi yang diharapkan dari kajian ini adalah bahwa penelitian ini dapat memperjelas pandangan tentang kualitas iman Abraham sehingga ia pantas disebut Bapa orang beriman?

\section{Kepribadian Abraham}

Pada awalnya di Mesir, Tuhan telah membuat janji-janji besar kepada Abraham tentang berkat, tanah, dan keturunannya. Sampai beberapa tahun sejak janji itu Tuhan sampaikan kepada Abraham, Tuhan belum 
memberitahu secara jelas bahwa pewaris Abraham akan datang melalui Sarah (walaupun Abraham seharusnya menganggap ini). Namun, ketika menghadapi krisis di Mesir, ketakutan memperngaruhi Abraham dan Sarah dan mereka lebih memilih melakukan muslihat, untuk melepaskan diri daripada percaya akan Tuhan untuk pembebasan. Abraham takut akan nyawanya dan mulai berspekulasi. Dia meminta Sarah untuk mengatakan bahwa dia adalah saudara perempuannya daripada istrinya - karena dia memang saudara tirinya sebagai permintaannya murni atas alasan pribadi.

Pada saat kejadian kedua terjadi di Gerar, Abraham sudah mengenal Tuhan jauh lebih baik (Kejadian 18: 9-15). Tetap saja, Abraham dan Sarah melakukan tipu muslihat daripada mencari Tuhan untuk pembebasan. Perlu dipahami bahwa tindakan Abraham ini bukan hanya semata-mata sebagai dusta namun juga dapat menjerumuskan Abraham dan Sarah kepada perzinahan. Dalam perjalanan Abraham sebagaimana Allah menyuruhnya keluar dari tempat asalnya, Abraham beberapa kali menunjukkan rasa takut yang justru di luar konteks iman jika Allah menyertainya.

Pada Kejadian 16:1-2. Abraham berusia 85 tahun, jadi ini terjadi sepuluh tahun setelah Allah menjanjikan seorang anak, dan lima belas tahun sebelum Ishak lahir. Allah tidak menyebutkan siapa yang akan menjadi si ibu - la hanya menyebutkan Abraham sebagai bapak! Mengingat bahwa Sarah tidak disebut sebagai si ibu, bagaimana kelihatannya tawaran Sarah ini? (Karena Allah tidak menggunakan dirinya untuk menggenapi janji-Nya (Sarah menduga), "mungkin" di benak Allah ada perempuan lain yang akan menggenapi janji tersebut. Sarah sepertinya tidak mementingkan diri, tidak sabar, dan ingin membantu Allah). Selanjutnya perhatikan pernyataan Sarah bahwa "TUHAN tidak memberi aku melahirkan anak?" Abraham, sebagai bapak orang beriman, mencoba untuk mempercepat rencana Allah. Tuhan telah berjanji kepada Abraham tanah dan sebuah keluarga, dan sejauh ini, Abraham tidak menerima keduanya. Jadi dalam Kejadian 16, Abraham mencoba untuk menyediakan sebuah keluarga untuk dirinya sendiri daripada percaya dan menunggu Tuhan. Padahal Tuhan telah berjanji pada Abraham anak laki-laki tetapi Sarah menyadari bahwa dia mandul dan mencari cara 
alternatif untuk melaksanakan rencana Tuhan. Meskipun Abraham tidak pernah berencana mengambil istri kedua dan tetap taat kepada Tuhan, namun pada akhirnya Sarah memberi seorang pelayannya yang bernama Hagar untuk memberikan keturunan bagi Abraham. Ketika seorang pria tidak dapat memiliki anak laki-laki dengan istrinya, maka adalah hal yang wajar apabila dia akan mengambil istri lagi untuk dirinya sendiri. Jika dia tidak dapat memiliki anak, dia akan mengambil istri lagi. Namun benarkah Allah berkenan akan perbuatan seperti itu?

Namun ada hal yang lebih menarik untuk dipahami dalam hal Sarah memberikan Hagar kepada Abraham, Abraham tunduk pada perkataan Sarah, yang memanfaatkan Hagar dengan maksud untuk mendapatkan keturunan. Sementara Abraham sendiri mengijinkan Sarah untuk memperlakukan Hagar sesuai yang dia pandang baik, namun dalam Kejadian 16:6 dituliskan bahwa Sarah "menindas" Hagar. Kata Ibrani dari menindas ini adalah va-t'anneha Ini 'umumnya membawa konotasi kerusakan fisik: itu bisa berarti. . . untuk menindas. . . serta hanya untuk merendahkan atau menghinakan." Seorang pengamat modern mencatat, 'Hagar adalah korban Sarah dan Sarah salah memaksakan peran padanya dan kemudian menyesali dia karena telah memainkannya terlalu baik ${ }^{8}$

Dalam hal di Mesir dan di Gerar Allah campur tangan untuk melepaskan Abraham jatuh ke dalam tindakan perzinahan namun mengapa justru ketika Sarah memberikan pelayan perempuannya, mengapa justru Allah terkesan membiarkan? Abraham memiliki kisah yang cukup merumitkan untuk dinilai memiliki kepribadian yang seimbang dengan imannya.

Pada titik ini apakah Abraham dan Sarah akhirnya memperoleh apa yang mereka ingingkan, tetapi apakah itu merupakan kehendak Allah? Namun keadaan di atas tidak bertahan lama, hal yang lebih buruk terjadi, Abraham 'melarikan diri' dari posisinya sebagai pemimpin. Sarah

\footnotetext{
${ }^{7}$ Jo Ann Hackett, "Rehabilitating Hagar: Fragments of an Epic Pattern" in Peggy L. Day, ed., Gender and Difference in Ancient Israel (Minneapolis:Fortress, 1989), hal 14.

${ }^{8}$ Elie Wiesel, "Ishmael and Hagar" in Joseph Edelheit, ed. The Life of Covenant (Chicago: Spertus College of Judaica Press, 1986) hal 238.
} 
memperlakukan Hagar dengan kejam. Tak seorangpun dari pasangan ini yang bertindak sebagaimana layaknya pengikut Allah. Dalam 17:15-17 Berapa tahun telah berlalu tanpa penggenapan janji Allah. Dalam ayat 17 Abraham kemudian menertawakan janji tersebut karena tampaknya janji itu tak berarti lagi kemudian ketika janji itu diulangi lagi Sarah juga mengeluarkan tawa cemooh (Kejadian 18:10-12), Pada tahapan "iman" yang bagaimana Abraham kini berada? Allah menunggu sampai pasangan ini "mati pucuk" baru memberi mereka anak yang dijanjikan. Apakah fakta ini membantu menjelaskan ihwal penantian mereka? Ini merupakan pola berulang yang terjadi saat Allah berurusan dengan manusia. la menunggu sampai suatu hal menjadi tidak mungkin, lalu kemudian la menjadikannya mungkin - agar tak seorang pun meragukan peran Allah dalam persoalan tersebut. Namun di Kejadian 21:6-7 Pada akhirnya Allah memperhatikan Sara dan memberikan anak di usia tuanya. Namun sekali peristiwa Sarah melihat ketika Ismael mengolok-olok Ishak, kemudian sarah meminta Abraham mengusir Hagar dan juga Ismael yang juga adalah darah dagingnya sendiri. Pantaskah nama Abraham dipahatkan di atas batu dalam "pasal iman" (Ibrani 11). Dalam hal ini Abraham terlihat tidak adil dalam membuat keputusan dalam rumah tangganya dengan mengusir Hagar dan Ismael yang merupakan darah dagingnya.

\section{Kualitas Iman Abraham}

Ibrani 11: 6 mengatakan kepada kita bahwa kita tidak bisa menyenangkan Allah tanpa iman. Anda dan saya harus mencari iman untuk menyenangkan Tuhan.

Lester Sumrall dalam bukunya memaparkan "

Faith is not to benefit ourselves altogether, but to please God. What then is faith? It is a knowledge of God. The amount of your faith is in direct relationship to your experience and knowledge of God. ${ }^{9}$

Iman bukan untuk menguntungkan diri kita sama sekali, tetapi untuk menyenangkan Tuhan. Lalu apa itu iman? Itu adalah pengetahuan tentang

${ }^{9}$ Lester Sumrall, Abraham Faith Under Siege, (United States of America, LeSEA Publishing Company: 1985), hal 7 
Tuhan. Jumlah iman Anda dalam hubungan langsung dengan pengalaman dan pengetahuan Anda tentang Tuhan.

Usia Abraham 75 tahun (Kejadian 12:4) saat pertama kali menerima janji dari Allah bahwa ia akan menjadi "bangsa yang besar. Kemudian di Kejadian 15:1-3, jadi dia meninggalkan negrinya di belakang dalam ketaatan kepada Tuhan.

Butuh waktu 25 tahun bagi Abraham untuk memiliki anak melalui istrinya, Sarah, tetapi Alkitab memberi tahu kita bahwa, terlepas dari ini periode waktu yang besar, iman Abraham tidak goyah. Rom 4: 18-22 memberi tahu kita bahwa "Melawan semua harapan, Abraham dengan harapan percaya ... Tanpa melemah dalam imannya, ia menghadapi kenyataan bahwa tubuhnya sudah mati - sejak berusia sekitar seratus tahun - dan bahwa rahim Sarah juga mati. Namun dia tidak goyah melalui ketidakpercayaan tentang janji Tuhan, tetapi diperkuat dalam imannya dan memuliakan Allah, sepenuhnya diyakinkan bahwa Tuhan berkuasa untuk melakukan apa yang telah dijanjikan kepadanya. Inilah sebabnya mengapa hal itu diperhitungkan kepadanya sebagai kebenaran ". Karena ia memegang imannya dalam janji Allah akan seorang putra, Abraham dinyatakan sebagai orang benar.

Dilihat dari respon Abraham, apakah respons-nya menunjukkan imannya? Abraham serta merta mengatakan Allah tidak menepati janji-Nya dan telah diatur bahwa kepala pelayannya yang akan mewarisi "upah besar" milik Abraham. Dalam Kejadian 12;15, Abraham mengalami dua tingkatan iman. Yang pertama adalah menerima dan menunggu dengan sabar. Yang kedua adalah menuntut Allah agar menepati janji-Nya. Dua-duanya samasama memandang Allah sebagai Oknum yang sanggup melakukan. Seterusnya dalam Kejadian 15:4-6 apakah Firman Allah yang menghidupkan kembali imannya terhadap janji tersebut? Bukankah pada tingkatan yang kedua tindakan menuntut Allah seolah-olah menunjukkan bahwa Abraham mulai menyangsikan Allah?

Sementara menurut Ibrani 11:11-12 memberikan puji-pujian kepada iman Abraham terhadap janji bahwa ia akan memperoleh keturunan yang 
banyak. Namun dilihat dari realitas perkawinan Abraham dan Sarah, dan hubungan mereka dengan Allah, tampaknya agak berbeda dengan gambaran iman yang sempurna. Apa yang bisa disimpulkan? Apakah penulis kitab Ibrani sedang mengenakan kacamata kuda? Ataukah, bahwa Allah itu lebih baik hati dan murah hati dari yang disangka terkait keputusankeputusan yang diambil dalam perkawinan dan dalam hubungan manusia dengan-Nya? bagaimana dengan pernyataan Paulus dalam Roma 4:18-21 (The New Bible Commentary, Paulus mengutarakan "bahwa Abraham bukan hanya seorang yang sempurna atau tanpa punya keraguan sedikit pun, tetapi bahwa sikap hatinya tetap satu dalam iman dan pengharapan akan janji Allah. Benarkah demikian?

Benarkah Abraham memiliki gambaran iman sempurna seperti yang dipaparkan oleh Paulus? Sementara Soren Kierkegaard dalam bukunya menuliskan bahwa Abraham sebagai "pahlawan iman" ${ }^{10}$ mungkinkah tolok ukur iman hanya sekedar retorika Paulus, sementara Surat Yakobus menuliskan bagaimana sesungguhnya iman itu harus disertai perbuatan yang sepadan dengan iman itu jika tidak pada hakekatnya iman itu adalah iman yang mati.

Apakah iman adalah sesuatu yang telah ditetapkan dan tidak berubah-ubah? Atau apakah iman adalah sesuatu yang aktif dan mengalami perubahan? Apakah iman adalah sebuah kesatuan pengetahuan yang harus ditaklukkan (untuk menjadi ahli)? Apakah iman adalah sebuah gaya hidup? Atau apakah iman itu adalah pengetahuan dan sekaligus gaya hidup? Apa yang tejadi dengan pengetahuan dan gaya hidup dari iman itu saat menjadi dewasa? Apakah iman yang berkualitas berarti menjadi semakin dekat /intim dengan Allah dan memperdalam hubungan seseorang dengan Allah? Apakah ada cara lain untuk dapat membentuk iman yang berkualitas? Pertanvaan-pertanvaan ini adalah inti dari kesatuan pengetahuan yang perlu dipahami untuk mengerti kualitas iman Abraham.

\section{Tujuan}

${ }^{10}$ Kierkegaard, Soren, Fear and Trembling, Translated by W. Lowrie, (Princeton University Press, Princeton, 1941), hal 64. 
Pertama, agar para orang Kristen memiliki suatu pandangan berdasarkan hermeneutik dan eksegesis yang objektif dan tepat, dan tidak sekadar mengikuti kecenderungan (trend) pemikiran teologis yang sedang berkembang. Di sisi lain, para teolog akan dapat memberikan jawab yang tepat kepada semua pihak yang menanyakan berbagai hal seputar pribadi dan Iman Abraham. Hal ini sesuai dengan nasihat Petrus dalam suratnya I Petrus 3:15, yang berbunyi: "Dan siap sedialah pada segala waktu untuk memberi pertanggunganjawab kepada tiap-tiap orang yang meminta pertanggungan jawab dari kamu tentang pengharapan yang ada padamu, tetapi haruslah dengan lemah lembut dan hormat..."

Kedua, bagi kaum awam dalam hal teologi, penelitian ini akan membantu agar tidak mudah terbawa arus oleh berbagai pandangan mutakhir tentang Iman Abraham, yang mungkin tidak didasarkan oleh penelitian yang objektif dan dapat dipertanggungjawabkan. Meskipun mungkin tidak memiliki latar belakang pendidikan teologis, namun dengan pesatnya perkembangan teknologi informasi, kaum awam pun dapat mengakses berbagai informasi dengan mudah.

\section{Metode Penelitian}

Untuk mendapatkan kebenaran sebagaimana dinyatakan dalam tujuan penelitian, maka digunakan beberapa metode berikut:

Metode Pengumpulan dan Pengolahan Data

1. Metode Studi Teks atau Studi Pustaka

Studi teks merentang dari studi teks disiplin ilmu-ilmu kemanusiaan tertentu atau studi pustaka, sampai ke studi tentang karya sastra. ${ }^{11}$ Maka akan digunakan prinsip-prinsip hermeneutis untuk naskahnaskah Perjanjian Lama sebagaimana dijelaskan oleh Stuart \& Fee.

2. Metode Historis Kritis ${ }^{12}$

\footnotetext{
${ }^{11} \mathrm{H}$. Noeng Muhadjir, Metodologi Penelitian Kualitatif, Edisi III. (Yogyakarta: Penerbit Rake Sarasin,1996), hal 103.

${ }_{12}$ David E. Aune, ed., The Blackwell Companion to the New Testament (West Sussex: John Wiley \& Sons Ltd., 2010), 101-104.
} 
Metode historis kritis digunakan untuk "mencari sumber-sumber sejarah atau kejadian masa lampau dalam membantu menerangkan kejadian masa kini dan mengantisipasi masa yang akan datang." ${ }^{13}$ Metode ini dipakai untuk menelaah pokok-pokok teologi yang menjadi fokus pembahasan dengan melihat aspek-aspek yang melatarbelakangi lahirnya pandangan tersebut dan perkembangannya dari masa ke masa, sehingga pandangan dalam bentuknya yang sekarang dapat dipahami. Dokumen- dokumen dan fakta-fakta sejarah yang relevan juga akan ditinjau untuk mendukung atau sebaliknya menyangkal suatu pandangan yang dikemukakan. Dokumen Pontifical Biblical Commission 1993 mengatakan tentang historical criticism sebagai berikut: "Itu adalah suatu metode kritik, karena dalam setiap langkahnya (dari kritik teks hingga kritik redaksi) itu berjalan dengan bantuan kriteria ilmiah yang berupaya untuk menjadi seobjektif mungkin". ${ }^{14}$ Dalam menggunakan metode historis kritis ini, penulis mengambil asumsi dasar bahwa Kitab Suci dilihat sebagai kitab yang kanonik dan dianggap sebagai norma (ukuran dasar) kebenaran.

3. Metode Analisa Konteks

Konteks berasal dari dua kata Latin, yakni "con" yang berarti bersamasama atau menjadi satu, dan "textus" yang berarti tersusun. ${ }^{15}$ Ayatayat atau ide yang dipakai dalam menyusun suatu teologi akan diuji makna sesungguhnya dengan menganalisa konteks dari ayat itu dalam perikop, kitab dan keseluruhan Alkitab.

4. Metode Komparasi

Menurut Kamus Besar Bahasa Indonesia, komparasi berarti perbandingan, dan komparatif berarti "berkenaan atau berdasarkan perbandingan". ${ }^{16}$ Metode ini dipakai untuk menemukan kebenaran melalui perbandingan di antara beberapa sumber. Misalnya suatu teks

\footnotetext{
${ }^{13}$ Sumanto, Metode Pendidikan dan Penelitian (Jogjakarta: Andi Offset, 1990), 43.

${ }^{14}$ Aune, 103.

${ }^{15}$ Hasan Sutanto, Hermeneutik: Prinsip dan Metode Penafsiran Alkitab (Malang: SAAT, 1988), 205.

${ }^{16}$ Pusat Bahasa Departemen Pendidikan Nasional, Kamus Besar Bahasa Indonesia,
} Ed. Ke-4. (Jakarta: Balai Pustaka, 2001), hal 719. 
dari Naskah Laut Mati dibandingkan dengan laporan sejarah dari Josephus atau hasil carbon dating, demikian seterusnya. Dengan demikian subjektivitas dalam berteologi dapat diminimalkan.

5. Metode Penarikan Kesimpulan

Penarikan kesimpulan dilakukan secara induktif, yakni dengan menyajikan premis-premis khusus untuk kemudian ditarik kesimpulan umum secara logis.

\section{Kesimpulan}

Dalam perjalanan imannya Abraham dalam keyakinannya sempat mengalami situasi batin yang kacau, namun hal itu bukanlah kegagalan iman. Dalam tujuan akhir dari iman tersebut hal yang Allah ingginkan dari Allah bukanlah kesempurnaan namun arah iman itu obyeknya siapa? perkara beriman bukanlah hanya sekedar perkara usia dan perjalanan iman tidak didudukkan dalam sebuah ruang hampa, juga bukanlah sebuah perjalan mulus yang setiap manusia mau, namun sebaliknya perjalanan iman tersebut teruji nilainya dalam menghadapi tantangan.

Menurut Pandangan penulis, di samping masalah kepribadian Abraham yang cukup kontroversial dengan kualitas imannya kepada Allah, Penulis mendapati nilai keyakinan yang eksistensial dalam diri Abraham sendiri. Kepercayaannya kepada Allah memampukannya untuk menjalani kehidupan pada taraf yang sama sekali di luar hidup keduniawian. Imannya begitu personal, memiliki kualitas ketenangan dimana akhirnya Abraham memutuskan pencarian akan makna kehidupan. Abraham tidak larut dalam situasi-situasi personal yang semu. Keputusan Abraham tanpa harus mengkompromikan keputusan untuk taat terhadap apa yang Allah katakan supaya mempersembahkan anaknya Ishak. Abraham berpegang teguh akan pengejaran akan kualitas iman secara progresif daripada hanya memikirkan tujuan ia hidup pada waktu itu.

Kenyataannya Abraham percaya kepada Allah bukan dengan tindakannya sendiri, Menurut Yohanes 6:28-29 bahwa iman adalah "pekerjaan" walaupun Abraham memiliki pekerjaan dan tindakan tersebut namun Abraham lebih 
mempercayai Allah daripada seberapa besar atau teguh dia dapat pecaya kepada Allah. Hal ini menjelaskan lebih jauh tentang iman bukanlah sesuatu yang kita usahakan namun semata-mata adalah karena hubungan kepada Allah.

Penulis memberi tekanan kepada apa yang menjadi dilema Abraham, dua kali ia berbohong bahwa Sarah bukan istrinya, dia juga pernah mempertanyakan Allah bahwa Sarah tidak memiliki anak, dia menunjukkan iman yang lemah saat Sarah menawarkan untuk mengambil Hagar sebagai saran untuk menggenapi rencana Allah supaya Abraham memiliki keturunan. Dalam hal ini Abraham juga adalah manusia biasa yang juga pernah mengalami keraguan kepada janji Allah, namun semuanya tidak berhenti di sana. Dalam kesabaran Allah, akhirnya dalam keadaan yang tidak ada dasar berharap Abraham akhirnya menetapkan hatinya untuk bergantung kepada kehendak Allah (Roma 4:18-22). Ini merupakan titik tolak kesadaran Abraham dalam meyakini Allah pada akhirnya secara eksistensial bukan lagi hanya bergantung kepada muzijat yang Allah bisa kerjakan untuknya dan keturunannya, namun Abraham menunjukkan kepada generasi selanjutnya akan kualitas iman yang dia miliki bukan lagi bergantung kepada situasi yang dia alami.

Bahkan iman Abraham teruji saat Allah meminta supaya Abraham mempersembahkan anaknya kepada Allah sebagai korban persembahan. Dia percaya bahwa Allah sanggup membangkitkan anak perjanjiannya jika ia mempersembahkan kepada Allah yang memberi perintah kepadanya. Fakta ini menjelaskan bahwa Iman Abraham bukan justru mengalami kekacauan namun sebaliknya imannya terus bertumbuh.

Allah tidak memilih untuk melaksanakan rencana-Nya melalui Abraham karena ia istimewa, berbakat, atau bahkan saleh. Kenyataannya, Tuhan tidak memilih siapa pun di dalam Alkitab untuk alasan itu; Dia juga tidak memilih siapa pun hari ini untuk alasan itu. 